\section{Cuatro años más ${ }^{1}$}

\author{
George A. O. Alleyne
}

1 Presentado el 23 de septiembre de 1998 en Washington, D.C., en la 25. Sesión de la Conferencia Sanitaria Panamericana, donde los Gobiernos Miembros reeligieron al doctor Alleyne al cargo de Director por un período de cuatro años.
En primer lugar, les doy las gracias, Señores Ministros y Jefes de Delegación, por la forma en que recibieron mi candidatura y por haber depositado su confianza en mí al elegirme de nuevo Director de la Oficina Sanitaria Panamericana y proponer mi nombramiento como Director de la Oficina Regional de la Organización Mundial de la Salud para las Américas. Ustedes me han brindado una oportunidad que se les presenta a muy pocos: la de servir a los pueblos americanos por conducto de esta singular empresa común representada por la Organización Panamericana de la Salud. Me han conferido un honor especial y, al hacerlo, han honrado a mi país y a la Región que fue el crisol de lo que soy.

Nunca me cansaré de agradecerles estos últimos cuatro años que he disfrutado como Director de la OSP. Han sido ricos en experiencia y atesoro en el rincón más sagrado de mi corazón cientos de recuerdos que he compartido con muchos de ustedes.

Entre esos recuerdos se destacan entrevistas con presidentes y primeros ministros de los países de las Américas y debates acerca de la naturaleza de nuestra cooperación y de las maneras en que podemos servirles mejor. Ha habido muchas ocasiones de pompa y ceremonia, pero los momentos más valiosos para mí fueron aquellos en que juntos asistimos a actividades sencillas en lugares donde su gente, mi gente, vive, ama, trabaja y muere. Siempre recordaré a los niños de Tacuarembó en Uruguay, a la orgullosa gente de Pocrí en Panamá y a las mujeres de Chiclayo en Perú, que construyeron silos para proteger sus cosechas de cereales de las ratas que transmitían la peste; el patio de la casa de vecindad de Trench Town en Jamaica, donde Bob Marley solía preparar su atole de maíz. Podría seguir rememorando muchas otras ocasiones como esas. Fue allí, en esos lugares, donde pude oír, ver y sentir las diferentes formas en que estaba mejorando la salud de nuestros pueblos. Nuestra Organización está orgullosa de ser parte de esos esfuerzos.

Espero tener muchas otras experiencias como esas, pero tendrán que limitarse a los próximos cuatro años, porque a pesar de lo mucho que me gusta lo que hago y de que mis únicas intenciones son ver a la Organización Panamericana de la Salud seguir prosperando, no me volveré a presentar ante ustedes en estas circunstancias.

No obstante, permítanme eliminar cualquier malentendido de que los próximos cuatro años ser- 
virán solamente para consolidar el statu quo. Todavía queda mucho por hacer y hay que estudiar numerosas formas nuevas de cooperación.

Trataremos de velar por que estos cuatro años representen la culminación adecuada de un siglo de trabajo de la OPS. En 2002, cuando cumplamos cien años, quiero que la celebración se centre en lo que se ha hecho en las Américas en el terreno de la salud con el apoyo de la OPS. Serán 100 años de haber caminado juntos y por eso deseo que recordemos los éxitos, pero que, a la vez, hayamos aprendido de los obstáculos encontrados a lo largo del camino. Durante este período también debemos pensar en los cambios y ajustes que deben hacerse para que nuestra Organización perdure y sea útil a sus beneficiarios por 100 años más.

"Permítanme eliminar cualquier
malentendido de que los próximos cuatro
años servirán solamente para consolidar el
status quo. Todavía queda mucho por
hacer y hay que estudiar numerosas
formas nuevas de cooperación".

Ha sido motivo de preocupación para mí que este período que conduce al final del siglo y a un nuevo milenio pudiera llevar a nuestra Organización a las actitudes y percepciones caracterizadas por el síndrome llamado de fin de siècle. Los años de finales de siglo han tendido a caracterizarse o a verse ensombrecidos por malestar general, desesperación y decadencia, lo cual se ha reflejado en el arte, la literatura y, a veces, en el servicio público. Mi temor era que esos aspectos tan perniciosos de final de siglo, que pueden propagarse rápidamente gracias a los nuevos medios de comunicación, pudiesen haber llegado a nuestros países, a los sectores de la salud y a nuestra Organización. Afortunadamente, no hemos sufrido de ese síndrome. Nuestra Organización de hoy puede describirse como una entidad que ha reformulado su misión y replanteado su cooperación técnica -como prometí hace cuatro años- y que está integrada básicamente por hombres y mujeres que quieren participar a fondo en lo que se está haciendo y no se conforman con ser simples espectadores.

Los próximos cuatro años van a generar cambios en nuestro entorno externo que exigirán de nosotros respuestas y adaptación. Nuestra existencia y nuestro éxito durante los últimos noventa y seis años constituyen la manifestación de nuestra capacidad de respuesta y adaptación.

Hay indicios claros de que continuará el crecimiento demográfico en nuestra Región y de que ese crecimiento probablemente sea mayor entre los marginados y desposeídos. Sin duda alguna, tendremos que hacer frente a las amenazas de nuevas enfermedades y al temor de que las antiguas vuelvan a acosarnos. Debemos abordar los aspectos de salud de nuestras poblaciones que envejecen y la dependencia cada vez mayor de las personas de edad de una población joven cada más reducida. Vemos con aprensión los conflictos raciales y étnicos en varias partes del mundo y esperamos que ese mal contagioso no nos afecte en gran escala. Lucharemos para establecer y mantener políticas que conserven y protejan nuestro medio ambiente, pero siempre con una perspectiva antropocéntrica. Nos veremos involucrados en la revolución de la información y nos inquietará sobremanera el temor de que el fenómeno de las interconexiones nos desvincule de las interacciones humanas que nos caracterizan y definen fundamentalmente como personas. Sabemos que nuestras economías tendrán que sobrevivir los peligros de la globalización; muchos de nosotros nos sentimos indefensos ante esa fuerza poderosa y avasalladora, mientras observamos cómo nuestros Estados se reestructuran y se reforman.

Mas la salud no debe ser víctima de esa reestructuración y reforma. Debemos asumir la responsabilidad de movilizar la atención política necesaria hacia la necesidad de brindar cierta protección a esos servicios de salud que son, sin duda alguna, bienes públicos esenciales. Pero tal vez nuestra necesidad más urgente e inmediata sea la de examinar cuál debe ser nuestra posición como Organización para hacer frente a ese miasma económico que parece estar envolviendo a todo el mundo. La inestabilidad y la inseguridad económicas amenazan arrasar con décadas de trabajo y de sacrificios de millones de nuestros ciudadanos. En los años ochenta examinamos cómo nos había afectado la crisis. ¿Tendremos que sufrir una vez más después de ocurridos los hechos y tratar de reparar el daño causado por una reforma y una reestructuración que parecía no haber considerado para nada a la salud?

Empero, debo confesar que el escenario que me sigue preocupando cada vez más es el que se refiere a las brechas crecientes entre la gente. De lo que he escuchado en los últimos cuatro años y especialmente en los últimos dos días, ustedes están igualmente preocupados. Es esa brecha la que me llevó hace cuatro años a declarar sin equivocación o reservas que uno de los principios de valor fundamentales que sustentaría mi administración sería la 
búsqueda de mayor equidad en el terreno de la salud, y que esas brechas que son innecesarias e injustas deberían cerrarse.

El paso del tiempo no ha modificado mi adhesión a ese valor. No obstante, he entendido mucho mejor la naturaleza de la tarea que es necesario emprender para que ese principio de valor sea más pertinente. Ahora percibo mejor que la equidad no significa más servicios de baja calidad para los pobres. Entiendo con más claridad que tendrá que haber equidad en la prevención de la mala salud y en la promoción de la buena salud. Soy más consciente de la necesidad de actuar según la premisa de que la poca equidad de los factores que determinan la salud es la causa originaria de las desigualdades que consideramos injustas en los resultados de salud. Veo con mayor claridad la función de las autoridades sanitarias y de la OPS en la búsqueda de la equidad, y me complace observar que hay algo más que una oleada pasajera de entusiasmo en cuanto a lo acertado de esta inquietud, en particular aquí en las Américas, donde la falta de equidad es mayor.

"Tendrá que haber equidad en la
prevención de la mala salud y en la
promoción de la buena salud".

El Presidente del Brasil, Fernando Henrique Cardoso, al referirse al desarrollo con rostro humano por medio de la equidad, escribió:

Nos encontramos frente a una paradoja: Cada vez se exige más la equidad, en parte como resultado de la globalización de la información, pero esta exigencia se plantea a un Estado que está reduciendo sus funciones y que tiene menos control sobre sus opciones de política económica. La exigencia de equidad - concepto clave en la transición de los imperativos de la eficiencia económica al ámbito de la acción social- no es nueva.

Más adelante, en lo que podría considerarse como un reto para nosotros aquí, dice:

El principal reto que se plantea a las organizaciones multilaterales es reinventar el sentido de comunidad y dar cabida a la solidaridad internacional.

Esta solidaridad, esta aptitud para lo pequeño y lo grande, para que ricos y pobres trabajen juntos en pro de la salud es algo muy valioso. Mi esposa me dice que casi le brotaron las lágrimas cuando vio a los equipos de fútbol de Argentina y Jamaica, de pie uno junto al otro, en Francia. Estaban allí como competidores, pero compartiendo una experiencia de mayor alcance; y yo quisiera que la contribución conjunta a una experiencia más amplia se hiciera más patente en nuestro enfoque panamericano de la salud en las Américas. Seguiremos insistiendo y estoy seguro de que con la ayuda de ustedes lo lograremos.

Si bien es cierto que tenemos metas concretas para la salud, este no es el lugar más indicado para exponerlas, ya que los detalles se presentan en las orientaciones estratégicas y programáticas que ustedes han aprobado. Sin embargo, hay algunas necesidades que casi pueden traducirse en un llamado a las armas.

Nos comprometeremos, por ejemplo, a evitar anualmente otras 25000 muertes de menores de un año durante los próximos cuatro años. Reanudaremos nuestro compromiso de mantener a nuestra Región libre de la poliomielitis y hacia el año 2002 confinar la erupción del sarampión a las fotografías que solamente tendrán un interés histórico para las nuevas generaciones de trabajadores de salud. Ningún hombre, mujer o niño debería estar expuesto a contraer una infección por Trypanosoma cruzi o VIH, o a sufrir de hepatitis o de sífilis por una transfusión de sangre. Se prestará cada vez mayor atención a las personas que tienen problemas de salud mental, que a menudo son olvidadas, y cada vez menos de nuestros ciudadanos fumarán.

Como fundamento para todo esto, refrendaremos nuestro compromiso con mayor firmeza para que en toda nuestra labor hagamos hincapié en la función clave de la información como eslabón decisivo en la cadena de datos, información, conocimientos y sabiduría. Seguiremos esforzándonos para que la cultura de producción y uso de la información se inserte firmemente en la trama de nuestras actividades.

Tal como prometiera hace cuatro años, hemos tendido la mano a una amplia gama de organismos, instituciones y organizaciones que comparten nuestros valores y nuestra preocupación por la salud. Pero esto no basta. Debemos ser más activos al abrazar la causa de la salud, no con el propósito de dar lustre a la imagen de la OPS, sino porque creo que debemos buscar un nuevo lugar para la salud, no en los pasillos del poder, sino en los recintos donde se toman las decisiones. La labor que realizan con nosotros los países, los organismos y las organizaciones refleja la confianza y el respeto que nuestra Organización se ha ganado a lo largo de su historia. En los próximos cuatro años buscaremos formas todavía más innovadoras de proyectar la 
imagen de nuestra labor colectiva y hacer que nuestros diferentes públicos la conozcan.

\section{"Debemos ser más activos en abrazar la causa de la salud. Debemos buscar un nuevo lugar para la salud, no en los pasillos del poder, sino en los recintos donde se toman las decisiones".}

Deseo que trabajemos con todos nuestros principales asociados a fin de establecer un programa común para la salud en las Américas para el año 2000. Aunque parezca sencilla, se trata en realidad de una tarea importante y audaz. Pero si aceptan el reto, será posible atraer a esas personas e instituciones de las Américas cuyas actividades tienen que ver con la salud para que se pongan de acuerdo sobre un marco de referencia básico donde puedan encajar muchas piezas.

Mantendré esa transparencia fiscal y programática que ustedes tienen todo el derecho de exigir, y garantizaré que la OPS cuente con las oficinas y los instrumentos para salvaguardar esa transparencia. La custodia de los recursos que recibimos de ustedes es una tarea sagrada. Mi trayectoria de los últimos cuatro años es tal que no tengo que referirme a la necesidad de que la mujer participe en todos los aspectos de esta Organización.

Incluiré al personal en mi planificación con el fin de simplificar nuestras prácticas y hacer los cambios que sean necesarios para asegurar que la Oficina responda mejor a las necesidades de los países.
Algunos de esos cambios van a incluir la incorporación de nuevas disciplinas en la Organización para hacer frente a los nuevos retos que se nos plantean.

Siempre somos conscientes de nuestra dependencia del compromiso de los países para darnos apoyo moral y financiero. Estoy orgulloso de la manera en que ustedes, nuestros Estados Miembros, apoyan a la OPS y confío en que en los próximos años ese apoyo continuará y aumentará de manera que esta Organización no se vea afectada por los recortes, pequeños pero dolorosos que, de continuar, pueden llegar a erosionar lo que ustedes han construido a lo largo de los últimos noventa y seis años.

Es con gran orgullo que he desempeñado el cargo de Director de la Oficina Sanitaria Panamericana y simultáneamente el de Director Regional de la Organización Mundial de la Salud y no quisiera que fuese de otro modo. Mi experiencia me ha convencido de que este arreglo da valor y realce a ambas Organizaciones y puedo asegurarles que haré todo lo que esté a mi alcance para no dividir lo que hemos unido en una relación productiva a lo largo de cincuenta años, relación que ha sido provechosa para los pueblos de las Américas y de todo el mundo.

Distinguidos Delegados, tengo muchas aspiraciones para la salud en las Américas y algunas veces, por el fervor de esas aspiraciones, hablo con una pasión que es inadecuada para mi imagen pública. No puedo esconderla. No puedo evitar hablar con pasión, pero me consuelo con las palabras del filósofo Hegel que cité en mi Informe Cuadrienal: "Nada grande se ha conseguido jamás en el mundo sin pasión".

Les doy las gracias una vez más y espero poder demostrarles que soy digno de la confianza de ustedes. 